\title{
OVIPOSITION DETERRENCE AND ADULT EMERGENCE INHIBITION ACTIVITIES OF CYMBOPOGON NARDUS AGAINST CULEX QUINQUEFASCIATUS WITH STUDY ON NON-TARGET ORGANISMS
}

\author{
ILAHI, I. ${ }^{1 *}$ - YOUSAFZAI, A. M. ${ }^{2}-$ HAQ, T. U. ${ }^{3}-$ ALI, H. ${ }^{1}-$ RAHIM, A. ${ }^{1}-$ SAJAD, M. A. ${ }^{4}-$ \\ KHAN, A. N. ${ }^{1}-$ Ahmad, A. ${ }^{1}-$ Ullah, S. ${ }^{5}-$ ZAMAN, S. ${ }^{5}-$ BIBI, A. ${ }^{1}-$ HuSSAIN, S. ${ }^{1}-$ RAHMAN, \\ M. U. ${ }^{1}-$ SAQIB, M. S. ${ }^{1}-$ AhMAD, B. ${ }^{1}-$ ATtaulla, M. ${ }^{1}$ \\ ${ }^{1}$ Department of Zoology, University of Malakand \\ Chakdara, Dir Lower, Khyber Pakhtunkhwa, Pakistan \\ ${ }^{2}$ Department of Zoology, Islamia College Peshawar \\ Peshawar, Khyber Pakhtunkhwa, Pakistan \\ ${ }^{3}$ Department of Biotechnology, University of Malakand \\ Chakdara, Dir Lower, Khyber Pakhtunkhwa, Pakistan \\ ${ }^{4}$ Department of Botany, Islamia College Peshawar \\ Peshawar, Khyber Pakhtunkhwa, Pakistan \\ ${ }^{5}$ Department of Botany, University of Malakand \\ Chakdara, Dir Lower, Khyber Pakhtunkhwa, Pakistan \\ ${ }^{*}$ Corresponding author \\ e-mail:ikramilahi@uom.edu.pk \\ (Received $5^{\text {th }}$ Nov 2018; accepted $25^{\text {th }}$ Jan 2019)
}

\begin{abstract}
The present study aimed to investigate the oviposition deterrent and adult emergence inhibition activities of non-polar solvent extract of Cymbopogon nardus whole plant against Culex quinquefasciatus mosquito with effect on non-target organisms. During the oviposition deterrent activity, the $1000 \mathrm{ppm}$ concentration of extract showed maximum (71.9 $\pm 3.3 \%)$ effective repellence (ER). The lowest concentration $(31.25 \mathrm{ppm})$ caused $13.4 \pm 1.3 \%$ ER. The oviposition activity index (OAI) of the gravid female $C x$. quinquefasciatus was estimated. For each concentration, negative OAI value was found. The negative OAIs values indicated that the n-hexane extracts of $C$. nardus whole- plant is oviposition repellent. Lowest OAI value was exhibited by $1000 \mathrm{ppm}$ extract solution. During the adult emergence inhibition (EI) activity, the $C$. nardus n-hexane extract solutions restricted adult emergence. There occurred $31 \pm 17.9 \%$ adult emergence from the containers containing $1000 \mathrm{ppm}$ extract solution. From the container containing $125 \mathrm{ppm}$ extract solution, $82.3 \pm 5.6 \%$ adult emerged. The $1000 \mathrm{ppm}$ of extract solution caused $66.2 \pm 19.5 \%$ EI. At $125 \mathrm{ppm}$ extract solution, $12.2 \pm 6.5 \%$ EI was observed. There was a positive correlation between extract concentration and $\mathrm{EI} \%(\mathrm{R}$ square $=0.86)$. The $\mathrm{EI}_{50}$ value of $C$. nardus was $515.2 \mathrm{ppm}$. During the study of effect of Cymbopogon nardus whole-plant n-hexane extract on non-target aquatic insects i.e., damselfly and dragonfly nymphs, the extract caused no mortality of any nymph up to $500 \mathrm{ppm}$. However, at $1000 \mathrm{ppm}$ concentration, the plant extract caused some mortality (5 $\%)$. During the study of effect of extract on grass carp fish (Ctenopharingodon idella), there occurred no mortality during 24-hour exposure. During the study of effect of extract on rabbits, there occurred no mortality and found no significant alterations in the normal biochemical and hematological parameters. Photomicrographs of microtome sections of liver and kidney of extract treated rabbit groups showed normal histoarchitecture. From the findings of the present research, it was concluded that the n-hexane extract of $C$. nardus whole-plant possesses oviposition deterrent and adult emergence inhibition activities against $C x$. quinquefasciatus. It was also concluded that the n-hexane extract of $C$. nardus whole plant is least toxic to damselfly and dragonfly nymphs. The extract does not cause mortality or behavioural
\end{abstract}


abnormality in fish. The ingestion of $C$. nardus whole-plant n-hexane extract in rabbits do not cause mortality or alterations in the normal biochemical and haematological parameters of rabbits.

Keywords: effective repellence, oviposition activity index, damselfly and dragonfly nymphs, grass carp, rabbit, biochemical and haematological parameters

\section{Introduction}

Mosquitoes are constant threats to human by transmitting several diseases such as malaria, filariasis, West Nile Virus infection, dengue fever and yellow fever (Farajollahi et al., 2011). Three genera viz; Anopheles, Aedes and Culex are more important as many of their species are vectors of diseases in human and other animals. Culex quinquefasciatus is a well-known culicine mosquito that causes serious nuisance through its irritating biting and is the vector of Wuchereria bancrofti, that causes lymphatic filariasis in humans (Rajasekariah et al., 1991). This disease has affected more than 100 million people in Asia, Africa, Central- and South America and the Pacific (Simonsen, 2009). In Pakistan, Beg et al. (2001) reported confirmed cases of tropical pulmonary eosinophilia in indigenous patients however this disease is very rare in Pakistan.

Synthetic chemical insecticides such as organochlorine and organophosphate compounds are commonly applied for the control of mosquitoes (Ghosh et al., 2012). The frequent application of synthetic chemical insecticides has caused the development of insecticide resistance in insect pests, contamination of the environment, and adverse effects on non-target organisms (Lee et al., 2001). Alternative approaches which are environment friendly should be adopted for controlling mosquito population (Ghosh et al., 2012). Biological control is the environment friendly and effectual means of managing pest. The biological control agents include some larvivorous fish (Walton, 2007), predatory insects (Mandal et al., 2008), protozoans (Das et al., 2016), bacteria (Phillips, 2001) and plants (Ajaegbu et al., 2016).

Plant-based insecticides have got attraction (Sivagnaname and Kalyanasundaram, 2004; Singh et al., 2006) as they are biodegradable, effective and environment friendly (Wang et al., 2000; Nerioa et al., 2010). Extracts of some plant have been reported for their larvicidal (Al-Mehmadi et al., 2010; Rawani et al., 2014), pupicidal (Kovendan et al., 2012), adulticidal (Jayapriya and Gricilda-Shoba, 2015; Ajaegbu et al., 2016) and insect repellent (Bekele and Petros, 2017) activities against mosquitoes.

In addition to the use of plants as general toxicants against mosquito larvae or adults, plant-based insecticides also deter the female adult mosquitoes from egg laying (Prajapati et al., 2005). The oviposition deterrent effect of plant extract may be due to the changes induced in the physiology and behavior of the female adult mosquitoes reflected by their egg-laying capacity. Some phytochemicals act as growth regulators or chemosterilent while some produce olfactory stimuli acting as repellent or attractant (Prathibha et al., 2014). The plants that possess insect repellent property may also exhibit oviposition deterrent and adult emergence inhibition properties (Rajkumar and Jebasan, 2009). The oviposition deterrent and adult emergence inhibition activities of some insecticidal repellent plant have been reported (Prathibha et al., 2014; Elango et al., 2012). The plant Cymbopogon nardus (Linn.) belongs to the family Poaceae and locally called Sargarai in Dir Lower, Khyber Pakhtunkhwa, Pakistan. The essential oil of $C$. nardus has been reported for its insect repellent activity against mosquitoes (Silva et al., 2011). The present study aimed to determine the oviposition deterrent and adult emergence inhibition activities of Cymbopogon nardus against Culex quinquefasciatus. 
Synthetic chemical insecticides also kill non-target organisms along with the target insect pests (Zacharia, 2011; Morrissey et al., 2015), but botanical pesticides are claimed to be safe or least toxic for non-target organisms (Rawani et al., 2014). Few studies have been conducted on the mosquitocidal activity of plant extracts in which the effect of plant extract on non-target aquatic insects (Chironomus) (Chowdhury et al., 2009), fish (Gambusia affinis) and tadpole (Bufo) (Adhikari et al., 2012) and even mammal (mice) (Carvalho et al., 2003) have been studied. According to the results of these studies, plant extracts appeared safe for non-target organism. The present research also aimed to study the effect of Cymbopogon nardus whole-plant n-hexane extract on non-target organisms i.e., damselfly and dragonfly nymphs and grass carp fish due to their habitat similarity with mosquito larvae. Synthetic chemical insecticides damage body organs in mammals if ingested (Tomlin, 2000; Soni et al., 2011). During the present research, the effects of oral administration of Cymbopogon nardus whole-plant n-hexane extract on some biochemical and haematological parameters of mammal i.e., rabbits were also studied.

\section{Materials and Methods}

\section{Preparation of plant extract}

Cymbopogon nardus (Linn.) whole-plant was collected from non-cultivated fields in Chakdara, Dir Lower Khyber Pakhtunkhwa, Pakistan and authenticated by an expert in plant taxonomy at the Department of Botany University of Malakand. The plants were shade dried and then ground into powder form by using electric grinder. During the present research, 1500 grams powder of $C$. nardus was soaked in $7500 \mathrm{ml}$ non-polar solvent i.e., n-Hexane in 15-liter plastic bucket. After soaking for three days, the plant material was filtered through Whatman filter paper 42. The filtrate was evaporated through rotary vacuum evaporator and extract in dense solution form was then poured from the bulb of rotary evaporator into a clean dry glass beaker and placed under running fan for an hour. Finally, n-hexane extract of $C$. nardus whole-plant was obtained in oily paste form.

\section{Laboratory rearing of Culex quinquefasciatus mosquito}

Colony of Cx. quinquefasciatus was established in the laboratory (Figure 1) at the University of Malakand, Chakdara, Dir Lower, Khyber Pakhtunkhwa, Pakistan. For this purpose, larvae of $C x$. quinquefasciatus were collected by using a rectangular plastic dipper (38 cm length, $28 \mathrm{~cm}$ width and $6.5 \mathrm{~cm}$ height) from a ditch containing stagnant water at the campus of university of Malakand. The larvae were brought in $700 \mathrm{ml}$ plastic containers with water from the collection site to the laboratory and reared for establishing a colony. The larvae were provided with larval food comprising of dog biscuit and dry yeast powder in the ratio of 3:2. The pupae emerged were transferred to a $500 \mathrm{ml}$ plastic jar containing $300 \mathrm{ml}$ non-chlorinated tap water and placed in mosquito cage $(45 \mathrm{~cm} \times 45 \mathrm{~cm} \times 45 \mathrm{~cm})$. The adults emerged were fed with carbohydrate food by providing cotton pad soaked in $10 \%$ sucrose solution. The female adult mosquitos laid eggs in the jar containing water inside the cage which then hatched into larvae. For confirmation of species proper literature was used for identification of both larvae and adults (Harbach, 1988). Powdered yeast and dog biscuit in 2:1 ratio was provided as food to the larvae. The adults obtained were initially provided with $10 \%$ sucrose and 
later blood fed periodically by allowing mice for eggs development. Larvae and adults of $C x$. quinquefasciatus were available.

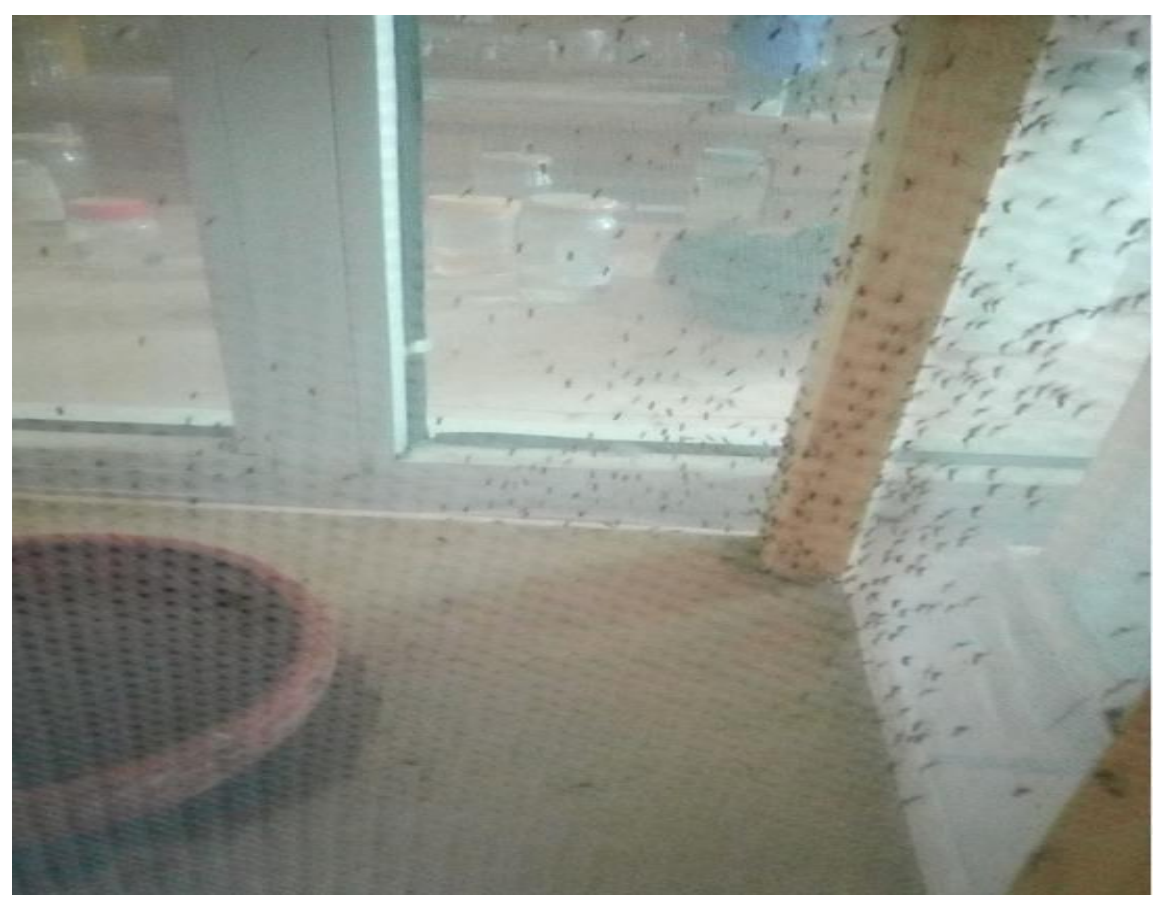

Figure 1. Picture of laboratory reared colony of Cx. quinquefasciatus established during the present experiments

\section{Oviposition deterrent bioassay}

During this bioassay, guidance was taken from the method of Xue et al. (2001). Three concentrations i.e., 1000, 250 and 31.25 ppm of $C$. nardus whole-plant n-hexane extract were selected during this study. The selection was based on the fact that these concentrations showed highest, moderate and lowest larval mortality during our study on larvicidal activity of $C$. nardus whole-plant n-hexane extract against $C x$. quinquefasciatus (Ilahi and Yousafzai, 2017). $1000 \mathrm{ml}$ stock solution of $2000 \mathrm{ppm}$ extract was prepared in non-chlorinated tap water in glass flasks containing $1.6 \%$ acetone and $0.05 \%$ tween 80 . From the stock solution, $200 \mathrm{ml}$ solution of $1000 \mathrm{ppm}$, $250 \mathrm{ppm}$ and $31.25 \mathrm{ppm}$ were prepared in three $400 \mathrm{ml}$ polyethylene containers by applying dilution equation, $\mathrm{C} 1 \mathrm{~V} 1=\mathrm{C} 2 \mathrm{~V} 2$. The 1000,250 and $31.25 \mathrm{ppm}$ extract solutions were placed inside the mosquito cages $\mathrm{A}, \mathrm{B}$ and $\mathrm{C}$, respectively. A control container containing $200 \mathrm{ml}$ non-chlorinated tap water with $1.6 \%$ acetone and $0.05 \%$ tween 80 was also placed inside each cage. The experiment was run in triplicates. Into each mosquito cage, 100 blood fed and gravid female $C x$. quinquefasciatus mosquitoes caught from the existing laboratory colonies were introduced. The mosquitoes laid eggs after 2 or 3 days of introduction. For each jar, total number of eggs and rafts were counted under dissecting microscope. The oviposition data was presented as percentage of effective repellence (ER \%) and oviposition activity index (OAI). Positive OAIs are considered as attractants, while negative OAIs are considered as repellents (Govindarajan et al., 2011). The ER \% was calculated by using the following method of Rajkumar and Jebasan (2009) (Eq.1): 


$$
-4919-
$$

$$
E R \%=\frac{N C-N T}{N C} \times 100
$$

Where ER: Effective repellency; NC: Number of eggs in control; NT: Number of eggs in treatment. The oviposition activity index (OAI) was calculated by using the following formula of Kramer and Mulla (1979) (Eq.2):

$$
O A I=\frac{N T-N C}{N T+N C}
$$

Where Nt: total number of eggs in the treatment container, Nc: total number of eggs in the control container. The oviposition data for each extract was presented as mean ER $\%$ and mean OAI.

Egg rafts and eggs of Cx. quinquefasciatus are shown in Figure 2 and Figure 3, respectively.

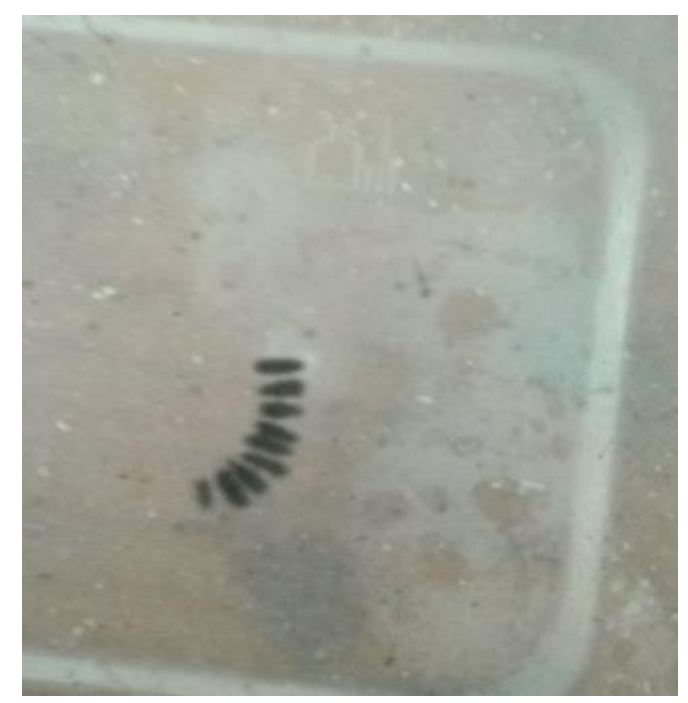

Figure 2. Egg rafts deposited by Culex quinquefasciatus during the present experiments

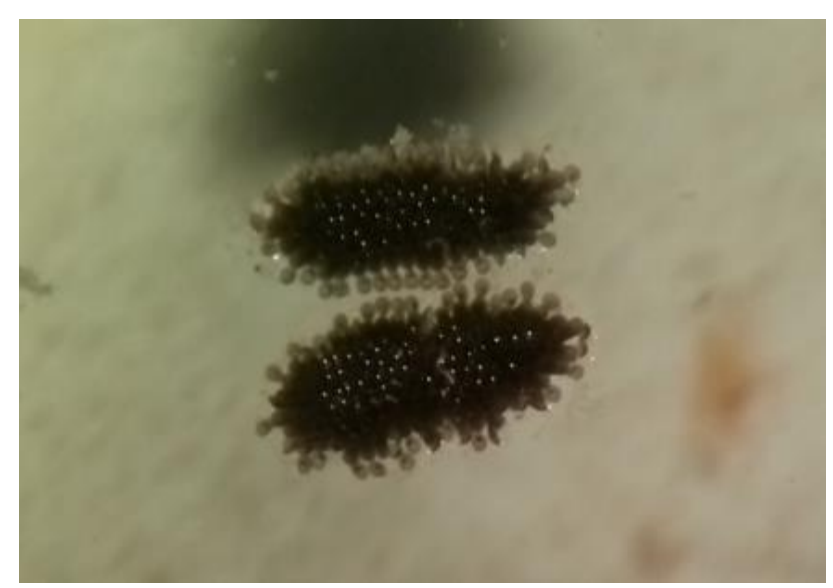

Figure 3. Microscopic picture of Culex quinquefasciatus eggs in rafts taken during the present experiments 


\section{Adult emergence inhibition bioassay}

During the present study, the effect of n-hexane extracts of $C$. nardus whole- plant on the adult emergence of $C x$. quinquefasciatus was studied in the laboratory at 1000 , 500,250 and $125 \mathrm{ppm}$. The selection of theses concentrations was based on the fact that these concentrations showed highest, moderate and lowest mortality during our study on larvicidal activity of $C$. nardus whole-plant n-hexane extract against $C x$. quinquefasciatus (Ilahi and Yousafzai, 2017). Guidance was taken from the work of Elimam et al. (2009) who followed the procedure for testing insect growth regulators. $300 \mathrm{ml}$ extract solutions of 1000, 500, 250 and $125 \mathrm{ppm}$ were prepared in four $600 \mathrm{ml}$ polyethylene containers from a $2000 \mathrm{ppm}$ stock solution containing $1.5 \%$ acetone and $0.05 \%$ tween 80 . A $600 \mathrm{ml}$ control polyethylene container containing $300 \mathrm{ml}$ nonchlorinated tap water (with $1.5 \%$ acetone and $0.05 \%$ tween 80 ) was also placed along each concentration. One hundred $3^{\text {rd }}$ instar larvae of $C x$. quinquefasciatus were transferred from the mosquito breeding containers to each treatment container. One hundred $3^{\text {rd }}$ instar larvae of $C x$. quinquefasciatus were also transferred to the control containers. This experiment was run in four replicates. The duration of the test was long therefore yeast was provided to each container as larval food at interval of two days. The jars were capped with gauze to prevent the escape of emerging adult mosquitoes. The jars were daily checked for the appearance of pupae and adults. The adults appeared were caught with the help of mouth aspirator and then put into a clean dry reagent bottle and anaesthetized by applying cotton swab soaked in diethyl ether. The experiment was conducted during 14-25 August 2016, and the maximum temperature inside the laboratory was $30^{\circ} \mathrm{C}$ to $34^{\circ} \mathrm{C}$. The observations were continued till all the larvae or pupae in the control have died or emerged as adults. At the end of experiment the number of adults emerged was noted for each treatment and control container. The number of adults emerged in control and each of the treatment containers was noted. The effect was expressed as percentage of emergence inhibition (EI \%). The EI \% was calculated by using the following formula used by Elimam (2007) (Eq.3):

$$
E I=100-\left[\frac{T \times 100}{C}\right]
$$

Where $\mathrm{T}$ represents percentage emergence in treatment container and $\mathrm{C}$ represents percentage emergence in the control container.

Adult emergence in control was more than $95 \%$ therefore there was no need of correction of data by abbot formula. Adult emergence inhibition data was presented as mean EI \%. The mean EI \% data was subjected to log probit analysis (Finney, 1971) for calculating $\mathrm{EI}_{50}$ (a measure of the extract concentration that caused $50 \% \mathrm{EI}$ ) value using SPSS 16 software.

\section{Effect of plant extract on non-target organisms}

During the present research, the effect of $C$. nardus whole- plant n-hexane extract on the following non-target organisms was also studied: 


\section{Effect on damselfly and dragonfly nymphs}

Damselfly (order Odonata, sub order Zygoptera) and dragonfly (order Odonata, sub order Anisoptera) nymphs of early instars (4 to 5 instar) were collected from the puddles on the bank of River Swat near the campus of University of Malakand. Collection of nymphs and experiments were conducted during August 2016 (maximum temperature $30-33^{\circ} \mathrm{C}$ ). Damselfly and dragonfly nymphs were collected from pond at the campus of University of Malakand by using a rectangular plastic dipper. The nymphs were transported in plastic jars containing water of the collection site to the laboratory at University of Malakand within 30 minutes of capture. In the laboratory, the nymphs along with water of collection site were transferred to a wide plastic tray (40 $\mathrm{cm}$ length, $30 \mathrm{~cm}$ width and $8 \mathrm{~cm}$ height). Before conducting experiments, the nymphs were fed with dried yeast powder and mosquito larvae. The specimens were identified to the species level with the help of literature (Gardner, 1960; Yousuf et al., 1996; Anjum, 1997; Mitra 2002; Din et al., 2013). Large number of nymphs were belonging to a damselfly species, Ischnura elegans and a dragonfly species, Sympetrum decoloratum.

During this study, $1000 \mathrm{ppm}$ solution of $C$. nardus whole- plant n-hexane extract was prepared in tap water containing $0.8 \%$ acetone and $0.02 \%$ tween 80 . This $1000 \mathrm{ppm}$ extract solution was serially diluted by factor of two, thus six solutions of 1000, 500, $250,125,62.5$ and $31.25 \mathrm{ppm}$ were arranged in $400 \mathrm{ml}$ polyethylene containers. Volume of testing solution in each polyethylene container was $250 \mathrm{ml}$. A $400 \mathrm{ml}$ polyethylene control container containing $250 \mathrm{ml}$ non-chlorinated tap water with $0.8 \%$ acetone and $0.02 \%$ tween 80 was also kept. For exposing the nymphs to the toxic effect of plant extract, the following method of Hardersen and Wratten (1996) was followed: seven intact $6^{\text {th }}$ to $7^{\text {th }}$ instar nymphs of each nymph species were placed separately in seven plastic containers (six extract concentrations and one control). In short, 14 containers were arranged for the nymphs of two odonate (damselfly and dragonfly) species, seven for each species. The experiment was run in triplicate and the period of exposure was 72 hours. Following standard toxicity protocols, the nymphs were not fed during the 72 hours exposure (ASTM standard E47, 2008). After 72 hours of exposure period, the numbers of dead and live nymphs were noted. The criterion for death was lack of response to prodding.

\section{Effect of plant extract on freshwater fish}

During this study, the toxic effect of $C$. nordus whole-plant n-hexane extract on fresh water fish was studied. Grass carp (Ctenopharingodon idella) was selected as test fish for this study because it is commercially important and is widely cultured in fish farms. Healthy grass carp fish of $11.6 \pm 1.3 \mathrm{~cm}$ length were brought from fish hatchery at Thana Malakand Agency to the laboratory in round plastic jar of $5.5 \mathrm{~L}$ volume. The jar was containing water of pond from which fish were collected. The time taken in bringing the fish to laboratory was less than 30 minutes. The fish were brought safe to the laboratory (no fish was died or sluggish). In the laboratory the fish were maintained in small fish aquaria (45 cm length, $40 \mathrm{~cm}$ width and $40 \mathrm{~cm}$ height) containing non-chlorinated tap water. The aquaria were receiving solar illumination through windows and oxygenated by using air pumps. Fish were exposed to a single concentration of $C$. nardus wholeplant n-hexane extract that was ten times higher than its LC50 value for $C x$. quinquefasciatus $4^{\text {th }}$ instar larvae during our study on larvicidal activity of $C$. nardus 
whole-plant n-hexane extract against $C x$. quinquefasciatus (Ilahi and Yousafzai, 2017). The LC50 value of $C$. nardus whole- plant n-hexane extract against $C x$. quinquefasciatus $4^{\text {th }}$ instar larvae was $599.6 \mathrm{ppm}$. The ten times value of LC50 was 5996 ppm. 20 liters extract solution of 5996 ppm concentration (containing $1.5 \%$ acetone and $0.05 \%$ tween 80 ) was prepared in non-chlorinated tap water in a fish aquarium $(45 \mathrm{~cm} \times 40 \mathrm{~cm} \times 40 \mathrm{~cm})$. A control aquarium containing non-chlorinated tap water with $1.5 \%$ acetone and $0.05 \%$ tween 80 was also arranged. Six grass carp fish were placed in each aquarium (total 12 fish in 2 aquaria). The behavior and mortality in fish of each aquarium was checked for 24 hours. After 24 hours, the extract solution in the aquarium was replaced with clean non-chlorinated tap water and observed for mortality for a further period of 24 hours. Experiment was conducted during August 2016 (maximum temperature $<33^{\circ} \mathrm{C}$ ).

\section{Effect of plant extract on rabbit (Oryctolagus cuniculus)}

During the present research, the effect of oral administration of high dose of $C$. nardus whole-plant n-hexane extract on some biochemical and hematological parameters were studied in rabbits. For this purpose, male domestic rabbits (Oryctolagus cuniculus) weighing 700-900 grams and 5-6 months of age were purchased from local market. They were housed in wide and well-ventilated chambers in Animal House at the University of Malakand, Khyber Pakhtunkhwa, Pakistan. The rabbits were fed on green vegetables and chaw pellets and allowed tap water ad libitum. The animals were kept in such condition for five days for acclimation before start of the experiments. In total, eight rabbits were divided into two groups ( $\mathrm{A}$ and $\mathrm{B}$ ), four in each. Rabbits of group A were orally administered $C$. nordus n-hexane extract in $4 \mathrm{ml}$ vegetable oil at a dose of $1000 \mathrm{mg}$ per $\mathrm{kg}$ body weight per oral. Group B was control and the rabbits of this group were orally administered only $4 \mathrm{ml}$ vegetable oil per $\mathrm{Kg}$ body weight per oral. The mortality and behavior of rabbits were monitored for 48 hours. This study was approved by University of Malakand Animal Ethics Committee. Experiment was conducted during September 2016 (maximum temperature $<31^{\circ} \mathrm{C}$ ).

After 48 hours, the animals were sequentially anesthetized with inhaled diethyl ether. Each rabbit restricted on the dissecting board was dissected and $3 \mathrm{~mL}$ blood was collected from the heart chambers by cardiac puncture with a 21 Gauge needle mounted on $5 \mathrm{~mL}$ syringe and then expelled gradually into Ethylene Diamine Tetra-acetic Acid (EDTA)-coated tubes for estimation of hematological parameters i.e., blood cells count (RBCs, WBCs and platelets count), and hemoglobin concentration. Another $3 \mathrm{ml}$ blood was collected by the same method in sterile tubes with coagulant for estimation of biochemical parameters i.e., ALT, AST, ALP, albumen and globulin. The data was presented as mean with standard error. The data was analyzed by un-paired sample Ttest for determining significant difference between the extract treated and control rabbit groups. For these analyses a computer software, SPSS 16 was used.

During this study the, liver and kidney tissues were processed for paraffin embedding and sections of 5-micron thickness were taken by a microtome. The sections were stained with hematoxylin and eosin, slides were prepared and then examined under microscope for histopathological changes and images were captured through attached CCTV camera. The data was presented as mean with standard error. The data was analyzed by un-paired sample T-test in One-Way ANOVA for determining significant difference between the extract treated and control rabbit groups. For these analyses a computer software, SPSS 16 was used. 


\section{Results}

\section{Oviposition deterrence}

Table 1 shows the range of number of eggs laid by the gravid female $C x$. quinquefasciatus adults in control containers and in extract solution containers (1000 ppm, $250 \mathrm{ppm}, 31.2 \mathrm{ppm})$. In control containers, the number of eggs was in the range 997-1937, in containers with lowest concentration (31.2 ppm), the number of eggs was in the range of 887-1614 but in containers with highest concentration (1000 ppm) of extract, the number of eggs was in the range of 287-707. Figure 4 shows the percentage of effective repellency (ER \%) of $C$. nardus whole-plant n-hexane extract against $C x$. quinquefasciatus. The highest concentration (1000 ppm) of $C$. nardus n-hexane extract greatly affected the egg laying capacity of the gravid female Cx. quinquefasciatus mosquito. Maximum ER \% was observed for the container containing 1000 ppm extract solution (ER \%=71.9 \pm 3.3 ) followed by $250 \mathrm{ppm}(\mathrm{ER} \%=44.3 \pm 7.4)$ and $31.25 \mathrm{ppm}(\mathrm{ER}$ $\%=13.4 \pm 1.3$ ). Table 1 also shows the oviposition activity indices (OAI) of each concentration of the $C$. nardus whole- plant n-hexane extract. The $1000 \mathrm{ppm}$ concentration of the plant extract exhibited minimum OAI value (mean OAI $=-0.5 \pm 0.1$ ) followed by $250 \mathrm{ppm}$ (mean $\mathrm{OAI}=-0.3 \pm 0.1)$ and $31.25 \mathrm{ppm}$ (mean $\mathrm{OAI}=-0.1 \pm 0)$.

Table 1. Effect of $C$. nordus whole-plant $n$-hexane extract on oviposition activity indices (OAI) of CX. quinquefasciatus

\begin{tabular}{c|c|c|c}
\hline Concentration (ppm) & No. of eggs (range) & OAI & Statistics \\
\hline 1000 & $287-707$ & $-0.5 \pm 0.1^{\mathrm{a}}$ & Sig= 0.005 \\
250 & $409-803$ & $-0.3 \pm 0.1^{\mathrm{ab}}$ & Df within \\
31.2 & $887-1614$ & $-0.1 \pm 0^{\mathrm{bc}}$ & groups $=9$ \\
Control & $997-1937$ & ---------- & F= 9.4 \\
\hline
\end{tabular}

Mean values with different letters represent significant difference at $\mathrm{P}<0.05$ significance level.

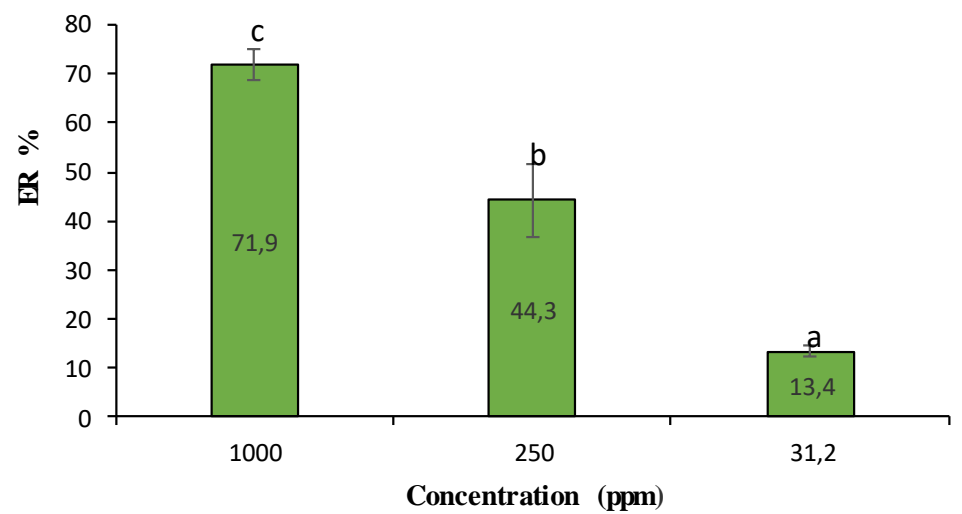

Figure 4. Effective repellency (ER \%) of C. nordus whole-plant n-hexane extract against $C x$. quinquefasciatus. Tukey test in One Way Anova. Df within group=9, F=38.2, Sig=0.000. Mean values with different letter represent significant difference at $P<0.05$ significance level

\section{Adult emergence inhibition}

Table 2 shows the adult emergence inhibition activity of $C$. nardus n-hexane extract against $C x$. quinquefasciatus. More than $90 \%$ emergence of adults occurred from the control containers. The emergence of adults was restricted in those containers that were 
containing $C$. nardus extract solutions. There occurred $31 \pm 17.9 \%$ adult emergence from the containers containing the highest extract concentration $(1000 \mathrm{ppm})$. There occurred $82.3 \pm 5.6 \%$ adult emergence from the containers containing the lowest extract concentration $(125 \mathrm{ppm})$. The highest extract concentration caused $66.2 \pm 19.5$ $\%$ emergence inhibition (EI), while the lowest extract concentration caused $12.2 \pm 6.5$ $\%$ emergence inhibition (EI). There was a positive correlation between extract concentration and $\mathrm{EI} \%$ (R square $=0.86$ ). The $\mathrm{EI}_{50}$ value of $C$. nardus was $515.2 \mathrm{ppm}$.

Table 2. Adult emergence inhibition activity of $C$. nordus against $C x$. quinquefasciatus

\begin{tabular}{c|c|c|c|c|c}
\hline $\begin{array}{c}\text { Concentration } \\
(\mathbf{p p m})\end{array}$ & $\begin{array}{c}\text { E \% in } \\
\text { treatment } \\
(\text { Mean } \pm \text { SE \%) }\end{array}$ & $\begin{array}{c}\text { E \% in } \\
\text { control } \\
\text { (Mean } \pm \text { SE) }\end{array}$ & EI \% (Mean \pm SE) & $\begin{array}{c}\text { R } \\
\text { Square }\end{array}$ & $\begin{array}{c}\text { EI50 } \\
(\mathbf{p p m})\end{array}$ \\
\hline 1000 & $31 \pm 17.9$ & $94.3 \pm 2.4$ & $66.2 \pm 19.5$ & & \\
500 & $43.8 \pm 16.8$ & $95.0 \pm 1.8$ & $54.0 \pm 17.7$ & 0.86 & 515.2 \\
250 & $66.5 \pm 14.4$ & $93.8 \pm 3.3$ & $29.3 \pm 13.8$ & & \\
125 & $82.3 \pm 5.6$ & $94.0 \pm 1.4$ & $12.2 \pm 6.5$ & \\
\hline
\end{tabular}

Mean values with different letter represent significant difference at $\mathrm{P}<0.05$ significance level.

\section{Effect on damselfly and dragonfly nymphs}

The effect of different concentrations of $C$. nardus whole- plant n-hexane extract on damselfly and dragonfly nymphs has been shown in Table 3. Up to $500 \mathrm{ppm}$ concentration, the $C$. nardus whole- plant n-hexane extract caused no mortality of damselfly or dragonfly nymphs. Only at $1000 \mathrm{ppm}$ concentration, the extract caused 3.3 $\pm 1.6 \%$ mortality of nymphs of each species, therefore table was not arranged for showing the effect of plant extract on non-target organisms. There also occurred no mortality in nymphs of control group.

Table 3. Effect of $C$. nardus whole plant n-hexane extract on non-target damselfly (Ischnura elegans) and dragonfly (S. decoloratum) nymphs

\begin{tabular}{c|c|c}
\hline Concentration (ppm) & I. elegans & S. decoloratum \\
\hline 1000 & $3.3 \pm 1.6$ & $3.3 \pm 1.6$ \\
500 & 0 & 0 \\
250 & 0 & 0 \\
125 & 0 & 0 \\
Control & 0 & 0 \\
\hline
\end{tabular}

\section{Effect on freshwater fish}

Grass carp fish, Ctenopharingodon idella, were exposed to 2040, 5007 and 5996 ppm concentration of $C$. ambrosioides, $C$. botrys and $C$. nardus whole- plant n-hexane extracts, respectively. The behavior and mortality of fish in each aquarium was checked for 24 hours. The extracts did not cause mortality in fish for 24 hours period of exposure.

\section{Effect of plant extract on rabbit}

During the present research, the effect of oral administration of high dose of $C$. nardus whole- plant n-hexane extract on the normal levels of some biochemical parameters i.e., 
ALT, AST, ALP and creatinine and hematological parameters i.e., RBCs, WBCs and platelets count, and hemoglobin concentration, of male domestic rabbits (Oryctolagus cuniculus) were studied. Each extract was orally administered to rabbit group (four rabbits in a group) at a dose of $1000 \mathrm{mg}$ per $\mathrm{Kg}$ body weight per oral. There occurred no significant change in the serum level of ALT, AST, ALP and creatinine of extract treated rabbit group when compared to control rabbit group ( $\mathrm{P}>0.05)$ (Table 4). Similarly, there occurred no significant change in the RBCs, WBCs and platelets count and hemoglobin concentration of extract treated rabbit group when compared to control rabbit group $(\mathrm{P}>0.05)$ (Table 5). The photomicrographs of liver and kidney microsections of extract treated rabbit groups showed normal histoarchitectures (Figure 5).

Table 4. Effect of larvicidal extracts (n-hexane extracts) of three whole-plant on some biochemical parameters of normal rabbits. $N=4$

\begin{tabular}{c|c|c|c|c}
\hline Plants & ALT $(\mathbf{U} / \mathbf{L})$ & AST $(\mathbf{U} / \mathbf{L})$ & ALP $(\mathbf{U} / \mathbf{L})$ & Creatinine $\mathbf{~ m g} / \mathbf{d l}$ \\
\hline C. nardus & $47.3 \pm 4.4^{\mathrm{a}}$ & $47.8 \pm 8.9^{\mathrm{a}}$ & $116.6 \pm 24.3^{\mathrm{a}}$ & $0.5 \pm 0.2^{\mathrm{a}}$ \\
Control & $51.0 \pm 3.2^{\mathrm{a}}$ & $52.3 \pm 6.1^{\mathrm{a}}$ & $113.7 \pm 11.6^{\mathrm{a}}$ & $0.4 \pm 0.05^{\mathrm{a}}$ \\
t value & -0.961 & -0.620 & -0.092 & 0.570 \\
DF & 6 & 6 & 6 & 6 \\
Significance (2-tailed) & 0.374 & 0.558 & 0.930 & 0.589 \\
\hline
\end{tabular}

Mean values with similar letter represent that there is no significant difference at $\mathrm{P}<0.05$ significance level.

Table 5. Effect of larvicidal extracts (n-hexane extracts) of three whole-plant on some haematological parameters of normal rabbits. $N=4$

\begin{tabular}{c|c|c|c|c}
\hline Plants & $\begin{array}{c}\text { RBCs } \\
(\mathbf{X ~ 1 0} / \boldsymbol{\mu} \mathbf{l})\end{array}$ & $\begin{array}{c}\text { WBCs } \\
(\mathbf{X ~ 1 0} / \boldsymbol{\mu l})\end{array}$ & $\begin{array}{c}\text { Platelets } \\
(\mathbf{X ~ 1 0} / \mu \mathbf{l})\end{array}$ & $\mathbf{H b}(\mathbf{g} / \mathbf{d l})$ \\
\hline C. nardus & $6.0 \pm 0.1^{\mathrm{a}}$ & $11.5 \pm 0.8^{\mathrm{a}}$ & $263.7 \pm 3.2^{\mathrm{a}}$ & $11.8 \pm 0.9 \mathrm{a}$ \\
Control & $5.9 \pm 0.2^{\mathrm{a}}$ & $11.9 \pm 0.7^{\mathrm{a}}$ & $273.3 \pm 14.3^{\mathrm{a}}$ & $11.6 \pm 0.5^{\mathrm{a}}$ \\
t value & 0.548 & -0.617 & -0.940 & 0.291 \\
DF within groups & 6 & 6 & 6 & 6 \\
Significance (2-tailed) & 0.604 & 0.560 & 0.383 & 0.781 \\
\hline
\end{tabular}

Mean values with similar letter represent that there is no significant difference at $\mathrm{P}<0.05$ significance level.
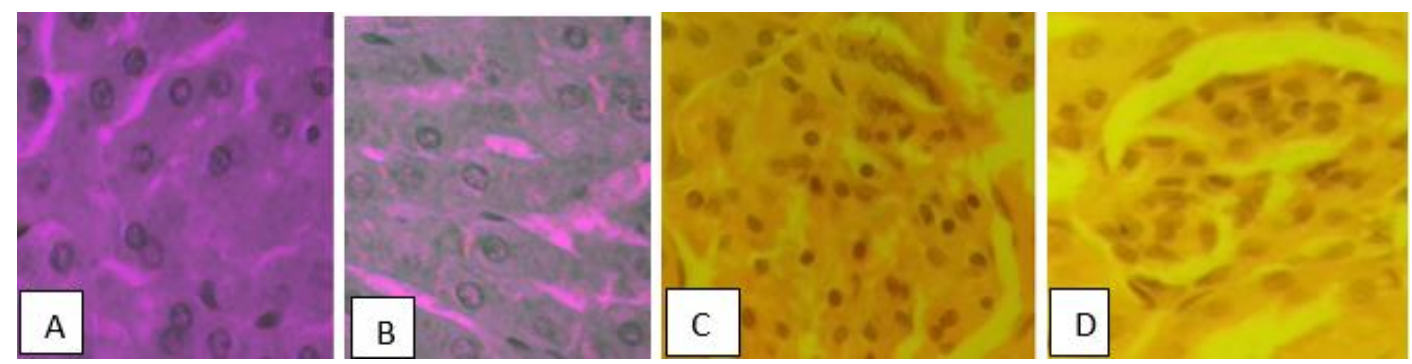

Figure 5. Photomicrographs showing normal histoarchitecture of rabbit liver and kidney microtome sections. The alphabets A to B represent photomicrographs of liver microtome sections of control and extract treated groups, respectively. These photomicrographs show normal hepatic histoarchitecture. The alphabets $C$ to D represent photomicrographs of kidney microtome sections of control and extract treated rabbit groups, respectively. These photomicrographs show normal renal histoarchitecture 


\section{Discussion}

During the present research, the n-hexane extract of $C$. nardus whole- plant showed oviposition deterrent activity against $C x$. quinquefasciatus mosquito. During the oviposition deterrent activity, most of the gravid female Cx. quinquefasciatus mosquitoes preferred to lay eggs in the control container or in the container that contain extract solution of lower concentration (Table 1). The extract solution of highest concentration was least preferred by the gravid female mosquitoes for oviposition. The oviposition deterrent activity was expressed in percentage of effective repellency (ER $\%$ ) and oviposition activity indices (OAI). Extract solution of highest concentration (1000 ppm) showed high ER \% whereas the extract solution of lowest concentration (31.2 ppm) showed low ER \% (Figure 4). The oviposition activity index (OAI) of the gravid female $C x$. quinquefasciatus at each tested concentration of extract was estimated (Table 1). Negative OAI value was observed at each tested concentration of plant extract. The negative OAIs values indicated that the n-hexane extracts of $C$. nardus whole- plant is oviposition deterrent (Govindarajan et al., 2011). Lowest OAI value $(-0.5 \pm 0.1)$ was exhibited by highest concentration $(1000 \mathrm{ppm})$ of extract solution. The oviposition deterrent activity of some plants against mosquitoes has been reported. For example, Reegan et al. (2015) reported that all the tested concentration of n-hexane extract of Limonia acidissima cause $100 \%$ ER against Cx. quinquefasciatus and Ae. aegypti. Elimam et al. (2009) studied the oviposition deterrent activity of aqueous leaves extract of Calotropis procera against gravid female Anopheles arabiensis and $C x$. quinquefasciatus. All the tested concentrations (1000, 500 and 200 ppm) caused more than $95 \%$ ER against An. arabiensis and Cx. quinquefasciatus. In the reported study of Elango et al. (2009), the OAI values of acetone, ethyl acetate, and methanol extracts of Aegle marmelos, Andrographis lineata and Cocculus hirsutus against Anopheles subpictus at 500 ppm were -0.86, -0.87, -0.90 -0.78, -0.87, -0.86, $0.91,-0.94$, and -0.86 respectively. Prathibha et al. (2014) studied the OAI value of Eugenia jambolana, Solidago canadensis, Euodia ridleyi and Spilanthes mauritiana against Ae. aegypti, An. stephensi and $C x$. quinquefasciatus. The OAI value of $E$. jambolana, S. canadensis, E. ridleyi and $S$. mauritiana at $100 \mathrm{ppm}$ against $C x$. quinquefasciatus were $-0.81,-0.84,-1.0$ and -1.0 , respectively. The oviposition deterrent effect of the plant extract may be due to the changes induced in the physiology and behavior of the adult mosquito species reflected by their egg-laying capacity (Prathibha et al., 2014). Some phytochemicals act as growth regulators or chemosterilent while some produce olfactory stimuli acting as repellent or attractant (Prathibha et al., 2014). Rajkumar and Jebasan (2009) reported that the plant extarcts that exhibited appreciable insect repellency were oviposition deterrent. Similarly, Mehra and Hiradhar (2002) reported that those plant extracts showed appreciable oviposition deterrent activity which were insect repellent.

During the present research, the n-hexane extract of $C$. nardus whole- plant showed adult emergence inhibition activity against $C x$. quinquefasciatus mosquito (Table 2). During this study, maximum emergence of adults occurred in the control containers $(>90 \%)$. Emergence of adults was restricted in those containers which were containing extract solutions. The percentage of adult emergence inhibition (EI \%) increased with increasing the concentration of extract solution. The EI 50 value of $C$. nardus wholeplant $\mathrm{n}$-hexane extract was $\mathrm{EI}_{50}=515.2 \mathrm{ppm}$. The biological activity of the plant extract might be due to the presence of various bioactive phytocompounds, including phenolics, terpenoids, and alkaloids, existing in plants, may jointly or independently contribute to 
produce adult emergence inhibition activity (Arivoli and Tennyson, 2011). The plant extracts have the potential to inhibit the growth of various developmental stages during the life histiorey of mosquitoes (Arivoli and Tennyson, 2011). Plant extracts have the potential to delay larval development, extend pupal duration, inhibit moulting, cause morphological abnormalities and mortality during moulting and melanization processes in mosquitoes (Shaalan et al., 2005). The adult emergence inhibition activity of some plants such as Abutilon indicum (Arivoli and Tennyson, 2011), Aegle marmelos, Andrographis lineata, Andrographis paniculata, Cocculus hirsutus, Eclipta prostrate and Tagetes erecta (Elango et al., 2012), Azadirachta indica (Howard et al., 2009), Eucalyptus citriodora (Singh et al., 2007) and Balanites aegyptiaca (Wiesman and Chapagain, 2006) has been reported against mosquitoes.

During the present study, the effect of $C$. nardus whole-plant n-hexane extract on non-target insects i.e., damselfly and dragonfly nymphs, fish i.e., grass carp and mammal such as rabbits was also studied. During the study of effect of extract on nontarget insects i.e., damsel and dragonfly nymphs, the extract caused no mortality of any nymphs up to $500 \mathrm{ppm}$. However, at $1000 \mathrm{ppm}$ concentration, the plant extract caused some mortality ( $5 \%$ ) of the nymphs (Table 3). This concentration of $C$. nardus wholeplant n-hexane extract caused $71.9 \%$ effective repellence during oviposition deterrent activity and $66.2 \pm 19.5 \%$ inhibition during adult emergence inhibition activity against $C x$. quinquefasciatus. These findings showed that $C$. nardus whole plant n-hexane extract is efficient ovipositor deterrent and adult emergence inhibitor against mosquitoes but least toxic for non-target insects such as damselfly and dragonfly nymphs.

During the study of effect of extracts on non-target grass carp fish (Ctenopharingodon idella), the extracts did not cause mortality in fish for 24 hours exposure. Few such studies have been reported in which the effect of plant extracts has also been studied on non-target organisms. For example, Chowdhury et al. (2009) studied the larvicidal activity of Solanum villosum leaves against Anopheles subpictus with effect on non-target Chironomus circumdatus larvae. The extract was found safe for the non-target $C$. circumdatus larvae. Adhikari et al. (2012) studied the repellent and larvicidal activities of Swietenia mahagoni against the Cx. quinquefasciatus larvae. They also studied the effect of the same extract on some non-target aquatic organisms i.e., Gambusia affinis, tadpole of Bufo and Chironomus larvae. They observed no toxicity of plant extract in these non-target organisms.

During the study on non-target mammals, the effects of oral administration of high dose of extract on some biochemical parameters i.e., ALT, AST, ALP and creatinine (Table 4) and some hematological parameters i.e., RBCs, WBCs and platelets count, and hemoglobin concentration (Table 5) were studied in domestic rabbit. There occurred no mortality and found no significant change in the biochemical and hematological parameters of rabbits. Photomicrographs of microtome sections of liver and kidney of extract treated rabbit groups showed normal histoarchitecture (Figure 5). Carvalho et al. (2003) reported the larvicidal efficacy of the essential oil from Lippia sidoides against Aedes aegypti. In addition, they also studied the toxicity of the essential oil in mice. They injected intraperitonially the diluted and pure form of hydrolate in amount of $30 \mathrm{ml}$ per $\mathrm{kg}$ body weight into the mice. The injection did not cause any adverse effects or mortality. The results of the present study revealed that $C$. ambrosioides, $C$. botrys and $C$. nardus whole- plant n-hexane extracts exhibit strong mosquitocidal activities but have no apparent deleterious effect on mammals (rabbit). 


\section{Conclusion and Recommendations}

1.) From the findings of the present research, it was concluded that the n-hexane extract of $C$. nardus whole-plant possesses oviposition deterrent and adult emergence inhibition activities against $C x$. quinquefasciatus. Further studies are recommended for elucidating the oviposition deterrent and adult emergence inhibition activities of $C$. nardus whole-plant $\mathrm{n}$-hexane extract against a wide range of mosquito species and exploring active compound responsible for such activities.

2.) It was also concluded that the n-hexane extract of $C$. nardus whole plant is least toxic to non-target insects i.e., damselfly and dragonfly nymphs. There occurs no mortality or behavioural abnormality in fish i.e., grass carp when exposed to high concentration of $C$. nardus whole-plant n-hexane extract. The ingestion of $C$. nardus whole-plant n-hexane extract do not cause mortality or alteration in the biochemical and haematological parameters of rabbits. The findings of our research encourage the use of botanical insecticides for mosquito control because they are ecofriendly and safe for non-target organisms.

Acknowledgements. This article has been prepared from a part of my (Ikram Ilahi) PhD thesis entitled "Ecofriendly control of Culex quinquefasciatus (say, 1823) and susceptibility of its larvae and predators to different environmental pollutants" at the Department of Zoology, Islamia College, Peshawar, Khyber Pakhtunkhwa, Pakistan.

\section{REFERENCES}

[1] Adhikari, U., Singha, S., Chandra, G. (2012): In vitro repellent and larvicidal efficacy of Swietenia mahagoni against the larval forms of Culex quinquefasciatus Say. - Asian Pac J Trop Biomed 2(1): 260-264.

[2] Ajaegbu, E. A., Danga, S. P. Y., Chijoke, I. K., Okoye, F. B. C. (2016): Mosquito adulticidal activity of the leaf extracts of Spondias mombin L. against Aedes aegypti L. and isolation of active principles. - J Vector Borne Dis 53: 17-22.

[3] Al-Mehmadi, R. M., Al-Khalaf, A. A. (2010): Larvicidal and histological effects of Melia azedarach extract on Culex quinquefasciatus Say. Larvae (Diptera: Culicidae). - Journal of King Saud University (Science) 22: 77-85.

[4] Anjum, S. A. (1997): Biosystematics of odonate naiads of the Punjab by rearing techniques. - M. Sc. thesis, Department of Agriculture Entomology University of Agriculture Faisalabad, Pakistan.

[5] Arivoli, S., Tennyson, S. (2011): Larvicidal and adult emergence inhibition activity of Abutilon indicum (Linn.) (Malvaceae) leaf extracts against vector mosquitoes (Diptera: Culicidae). - J Biopesticides 4 (1): 27-35.

[6] ASTM - American Society for Testing and Materials (2008): Guide for Conducting Acute Toxicity Tests on Aqueous Ambient Samples and Effluents with Fishes, Macroinvertebrates, and Amphibians. - ASTM International.

[7] Beg, M. A., Naqvi, A., Zamanand, V., Hussain, R. (2001): Tropical Pulmonary Eosinophilia and Filariasis in Pakistan. - Southeast Asian J Trop Med Public Health 32 (1): 73-75.

[8] Bekele, D., Petros, B. (2017): Repellent Effects of Aloe pirottae (Aloaceae) Gel Extract and Brassica nigra (Brassicaceae) Essential Oil against the Malaria Vector, Anopheles arabiensis Patton (Diptera: Culicidae). - Biochem Anal Biochem 6: 336. 
[9] Carvalho, A. F. U., Melo, Y. M. M., Craveiro, A. A., Machado, M. I. L., Bantim, M. B., Rabelo, E. F. (2003): Larvicidal Activity of the Essential Oil from Lippia sidoides Cham. against Aedes aegypti Linn. Mem. Inst. - Oswaldo Cruz, Rio de Janeiro 98 (4): 569-571.

[10] Chowdhury, N., Chatterjee, S. K., Laskar, S., Chandra, G. (2009): Larvicidal activity of Solanum villosum Mill (Solanaceae: Solanales) leaves to Anopheles subpictus Grassi (Diptera: Culicidae) with effect on non-target Chironomus circumdatus KieVer (Diptera: Chironomidae). - J Pest Sci 82: 13-18.

[11] Das, B. P., Deobhankar, K., Pohekar, K. N., Marathe, R., Husain, S. A. and Jambulingam P. (2016): Laboratory bioassay of Chilodonella uncinata, an entomopathogenic protozoan, against mosquito larvae. - Journal of Mosquito Research 6(10): 1-10.

[12] Din, A. U., Zia, A., Bhatti, A. R., Khan, M. N. (2013): Odonata naiads of Potohar Plateau, Punjab, Pakistan. - Pakistan J Zool 45: 695-700.

[13] Elango, G., Bagavan, A., Kamaraj, C., Abduz Zahir, A., Abdul Rahuman, A. (2009): Oviposition-deterrent, ovicidal, and repellent activities of indigenous plant extracts against Anopheles subpictus Grassi (Diptera: Culicidae). - Parasitol Res 105 (6): 156776.

[14] Elango, G., Rahuman, A. A., Kamaraj, C., Bagavan, A., Abduz Zahir, A. (2012): Adult emergence inhibition and adulticidal activity of leaf crude extracts against Japanese encephalitis vector, Culex tritaeniorhynchus. - Journal of King Saud University, Science 24: 73-80.

[15] Elimam, A. M. (2007): Larvicidal, ovicidal, oviposition deterrence and emergence inhibition activity of selected Sudanese plants against Anopheles arabiensis and Culex quinquefasciatus. - Ph.D. Thesis, Department of Biology, Faculty of Education University of Khartoum.

[16] Elimam, A. M., Elmalik, K. H., Ali, F. S. (2009): Efficacy of leaves extract of Calotropis procera Ait. (Asclepiadaceae) in controlling Anopheles arabiensis and Culex quinquefasciatus mosquitoes. - Saudi J Bio Sci 2 (16): 95-100.

[17] Farajollahi, A., Fonseca, D. M., Kramer, L. D., Kilpatrick, A. M. (2011): Bird biting" mosquitoes and human diseases: A review of the role of Culex pipiens complex mosquitoes in epidemiology. - Infect Genet Evol 11 (7): 1577-1585.

[18] Finney, D. J. (1971): Probit analysis. - Cambridge University Press, London: 68-78.

[19] Gardner, A. E. (1960): "A Key to the Larvae of the British Odonata". The New Naturalist Dragon flies. - Collins St. James, London: 190-225.

[20] Ghosh, A., Chowdhury, N., Chandra, G. (2012): Plant extracts as potential mosquito larvicides. - Indian J Med Res 135 (5): 581-598.

[21] Govindarajan, M., Mathivanan, T., Elumalai, K., Krishnappa, K., Anandan, A. (2011): Ovicidal and repellent activity of botanical extracts against Culex quinquefasciatus, Aedes aegypti and Anopheles stephensi, (Diptera: Culicidae). - Asian Pac J Trop Med 1 (1): 4348.

[22] Harbach, R. E. (1988): The mosquitoes of the Subgenus Culex in South West Asia and Egypt (Diptera: Culicidae). - Contribution of American Entomological Institute 24(1). https://apps.dtic.mil/dtic/tr/fulltext/u2/a512480.pdf

[23] Hardersen, S., Wratten, S. D. (1996): The sensitivity of the nymphs of two New Zealand Damsel fly Species (Odonata: Zygoptera) to Azinphos-Methyl and Carbaryl. - Australas J Ecotoxicol 2: 55-60.

[24] Howard, A. F., Adongo, E. A., Hassanali, A., Omlin, F. X., Wanjoya, A., Zhou, G., Vulule, J. (2009): Laboratory evaluation of the aqueous extract of Azadirachta indica (neem) wood chippings on Anopheles gambiae s.s. (Diptera: Culicidae) mosquitoes. - J Med Entomol 46 (1): 107-114.

[25] Ilahi, I., Yousafzai, A. M. (2017): Larvicidal, pupicidal and adulticidal activities of nonpolar solvent extract of Cymbopogon nardus (Linn.) whole plant against a mosquito, Culex quinquefasciatus (Say.). - Pak J Pharm Sci 30(6): 2337-2340. 
[26] Jayapriya, G., Gricilda-Shoba, F. (2015): Adulticidal and repellent activities of Rhinacanthus nasutus leaf extracts against Aedes aegypti Linn and Culex quinquefasciatus Say. - J Entomol Zool Stud 3(1): 154-159.

[27] Kovendan, K., Murugan, K., Vincent, S. and Barnard, D.R. (2012): Studies on larvicidal and pupicidal activity of Leucas aspera Willd. (Lamiaceae) and bacterial insecticide, Bacillus sphaericus, against malarial vector, Anopheles stephensi Liston. (Diptera: Culicidae). - Parasitol Res 110: 195-203.

[28] Kramer, W. L., Mulla, S. (1979): Oviposition attractants and repellents of mosquitoes: oviposition responses of Culex mosquitoes to organic infusions. - Environ Entomol 8: $1111-1117$.

[29] Lee, S. E., Kim, J. E., Lee, H. S. (2001): Insecticide resistance in increasing interest. Agric Chem Biotechnol 44: 105-112.

[30] Mandal, S. K., Ghosh, A., Bhattacharjee, I., Chandra, G. (2008): Biocontrol efficiency of odonate nymphs against larvae of the mosquito, Culex quinquefasciatus Say, 1823. Acta Trop 106: 109-114.

[31] Mehra, B. K., Hiradhar, P. K. (2002): Cuscuta hyalina Roth. and insect development inhibitor against common house mosquito Culex quinquefasciatus Say. - J Environ Biol 23: 335-339.

[32] Mitra, A. (2006): Current status of the Odonata of Bhutan: A checklist with four new records. - Bhu J RNR 2(1): 136-143.

[33] Morrissey, C. A., Mineau, P., Devries, J. H., Sanchez-Bayo, F., Liess, M., Cavallaro, M. C., Liber, K. (2015): Neonicotinoid contamination of global surface waters and associated risk to aquatic invertebrates: a review. - Environ Int 74: 291-303.

[34] Nerioa, L. S., Olivero-verbela, J., Stashenko, E. (2010): Repellent activity of essential oils: A review. - Bioresource Technol 110 (1): 372-378.

[35] Phillips, R. S. (2001): Current status of malaria and potential for control. - Cim Microbial Rev 14 (1): 208-226. doi: 10.1128/CMR.14.1.208-226.2001

[36] Prajapati, V., Tripathi, A. K., Aggarwal, K. K., Khanuja, S. P. (2005): Insecticidal, repellent and oviposition-deterrent activity of selected essential oils against Anopheles stephensi, Aedes aegypti and Culex quinquefasciatus. - Bioresource Technol 96 (16): 1749-1757.

[37] Prathibha, K. P., Raghavendra, B. S., Vijayan, V. A. (2014): Larvicidal, ovicidal, and oviposition-deterrent activities of four plant extracts against three mosquito species. Environ Sci Pollut Res 21: 6736-6743.

[38] Rajasekariah, G. R., Parab, P. B., Chandrashekar, R., Deshpande, L., Subrahmanyan, D. (1991): Pattern of Wuchereria bancrofti microfilaraemia in young and adolescent school children in Bessein, India, an endemic area for lymphatic filariasis. - Ann Trop Med Parasitol 85: 663-665.

[39] Rajkumar, S., Jebasan, A. (2009): Larvicidal and oviposition activity of Cassia obtusifolia Linn. (Family: Leguminosae) leaf extract against malarial vector, Anopheles stephensi Liston (Diptera: Cuoicidae). - Parasitol Res 104 (2): 337-340.

[40] Rawani, A., Ghosh, A., Chandra, G. (2014). Laboratory evaluation of molluscicidal \& mosquito larvicidal activities of leaves of Solanum nigrum L. - Indian J Med Res 140: 285-295.

[41] Reegan, A. D., Gandhi, M. R., Paulraj, M. G., Ignacimuthu, S. (2015): Ovicidal and Oviposition Deterrent Activities of Medicinal Plant Extracts against Aedes aegypti L. and Culex quinquefasciatus Say Mosquitoes (Diptera: Culicidae). - Osong Public Health Res Perspect 6 (1): 64-69.

[42] Shaalan, E. A. S., Canyonb, D., Younesc, M. W. F., Wahab, H. A., Mansoura, A. H. (2005): A review of botanical phytochemicals with mosquitocidal potential. - Environ. Int 31: 1149-1166. 
[43] Silva, C. F., Moura, F. C., Mendes, M. F., Pessoa, F. L. P. (2011): Extraction of Citronella (Cymbopogon nardus) essential oil using Supercritical $\mathrm{CO}_{2}$ : Experimental data and mathematical modeling. - Braz J Chem Eng 28 (2): 343-350.

[44] Simonsen, P. E. (2009): Filariases. - In: Cook, G. C., Zumla, A. I., (eds.) Manson's tropical diseases. 22. London, Saunders Elsevier: 1477-1513.

[45] Singh, R. K., Dhiman, R. C., Mittal, P. K. (2007): Studies on mosquito larvicidal properties of Eucalyptus citriodora Hook (family-Myrtaceae). - J commun Dis 39 (4): 233-236.

[46] Singh, R. K., Dhiman, R. C. and Mittal, P. K. (2006): Mosquito Larvicidal properties of Momordica Charantia Linn (Family: Cucurbitaceae). - J Vect Borne Dis 43: 88-91.

[47] Sivagnaname, N., Kalyanasundaram, M. (2004): Laboratory evaluation of methanolic extract of Atlantia monophyla (Family: Rutaceae ) against immature stages of mosquitoes and non-target Organisms. - Mem Inst Oswaldo Cruz, Rio de Janeiro 99(1): 6.

[48] Soni, I., Syed, F., Bhatnagar, P., Mathur, R. (2011): Perinatal toxicity of cyfluthrin in mice: Developmental and behavioral effects. - Hum Exp Toxicol 30(8): 1096-1105.

[49] Tomlin, C. (2000): The Pesticide Manual - British Crop Protection Council, Farnham, Surrey, UK, 12th edition.

[50] Walton, W. E. (2007): Larvivorous fisH including Gambusia. - J Amer Mosq Cont Assoc 23(2): $184-220$.

[51] Wang, C. H., Chang, N. T., Wu, H. H., Ho, C. M. (2000): Integrated control of the dengue vector Aedes aegypti in Liu-Chiu village, Ping-Tung County, Taiwan. - J Amer Mosq Cont Assoc 16 (2): 93-99.

[52] Wiesman, Z., Chapagain, B. P. (2006): Larvicidal activity of saponins containing extracts and fractions of fruit mesocarp of Balanites aegyptiaca. - Fitoterapia 77 (6): 420-424.

[53] Xue, R. D., Barnard, D. R., Ali, A. (2001): Laboratory and field evaluation of insect repellents as oviposition deterrents against the mosquito Aedes albopictus. - Med Vet Entomol 15: 126-131.

[54] Yousuf, M., Khan, M. J., Khaliq, A. (1996): Description of some final instar naiads (Libellulidae: Odonata) from Punjab and Sindh. - Pak Entomol 18 (1, 2): 17-23.

[55] Zacharia, J. T. (2011): Ecological Effects of Pesticides, Pesticides in the Modern World In: Stoytcheva, M. (ed.) Risks and Benefits, ISBN: 978-953-307-458-0. 